\title{
Universal Chemical Suit of Nonconductive Type Design
}

\author{
Guzel N. NURULLINA \\ Ph.D. (in Technical Sciences) \\ Associate Professor \\ Faculty of Textile Industry Technology and Fashion, \\ Textile Industry Materials and Technologies Department \\ Kazan National Research Technological University \\ 68, Karl Marx Str., Kazan, 420015, Russia \\ nur.guthel@inbox.ru \\ Venera I. BOGDANOVA \\ Ph.D. (in Technical Sciences) \\ Associate Professor \\ Faculty of Textile Industry Technology and Fashion, \\ Textile Industry Materials and Technologies Department \\ Kazan National Research Technological University \\ 68, Karl Marx Str., Kazan, 420015, Russia \\ bogdanovavi@mail.ru
}

\begin{abstract}
The article presents the results of research on special protective clothing against chemical factors. The study examines the respiratory elements used by employees engaged in harmful and dangerous working conditions, as well as the operational requirements for this type of product. Analysis of the breathing elements showed that they have different designs, dimensions and operating conditions, which makes it necessary to make special suits for each breathing apparatus. Businesses have to purchase several protective suits used with different breathing elements, which leads to significant financial costs. Based on the analysis of existing nonconducting suits, a universal chemical suit was developed that allows the use of various breathing apparatus. As a result of research the basic materials, tape for sealing joints, picked up the threads, defined by the length of the stitches selected combo type connection details of the costume. Special attention is paid to the connection of personal protective equipment for hands and feet with the overalls, taking into account the preservation of the suit's tightness. The description of the suit is given when it is used with various breathing apparatus (filtering, filtering hose type, nonconducting, chemically-connected oxygen, isolating, working on compressed air).
\end{abstract}

Keywords: suit of nonconducting type; sealing; breathing element; personal protective equipment; subcutaneous space.

\section{Introduction}

In accordance with the Labor Code of the Russian Federation and the Federal Law "On the Fundamentals of Labor Protection in the Russian Federation", "Rules for Providing Workers with Special Clothes, Special Shoes and Other Personal Protective Equipment", it is mandatory to provide employees with personal protective equipment. Depending on the type of influencing harmful or dangerous factor, the classification of personal protective equipment is presented in the technical regulations of the Customs Union "On the safety of personal protective equipment" (TR CU 019/2011) (2012). 
The ability to timely ensure the protection of people of all ages from the widest range of toxic chemical, biological and radioactive substances is the prerogative of federal and republican executive authorities, institutions', enterprises' and facilities' heads, regardless of the form of ownership and the specialists of municipalities' and cities' population civil protection departments and the Main Directorate of the EMERCOM of Russia (Personal protective equipment).

In the twenty-first century, people started to be increasingly focused on research and innovative development of even more reliable personal protective equipment from new materials. And in-depth research into the structure of the human body is materialized in chemical protection suits with a completely new ergonomic design. The production method is also changing: parts of the product are cut using more accurate patterns on computer controlled automated equipment.

Proper materials selection is a key factor in chemical protective clothing manufacture. Enterprises producing protective clothing faced the problem of non-compliance of materials with standards according to the basic characteristics. Over the years, there has been a steady upward trend in the number of offenses in the field of falsification and counterfeiting of materials for protective clothing.

In the field of thin reinforcing materials for fabric-film materials and rubberized fabrics production, first of all, it is necessary to pay attention to polyester fabrics with surface density of $4 \mathrm{~g} / \mathrm{m}^{2}$ that are mainly used for membrane fabrics and other special purposes. The fabrics are produced in heat-set form. Along with polyester fabrics, fabrics from polyamide and other synthetic threads up to 150 $\mathrm{cm}$ wide are also produced. Rubberized fabrics used in the manufacture of suits must have permission from the Ministry of Health of the Russian Federation for their use in personal protective equipment.

For workers employed in hazardous and dangerous working conditions, clothing is produced in the form of a nonconducting suit, or an open-type suit made of a suitable material, and a breathing element. Specific requirements are imposed due to the peculiarities of the operation of products (Zhuravleva 2011). The time of continuous use of the suit is determined by physical activity and is limited by the duration of the breathing apparatus (when using it). The suit should provide the worker's protection during the entire standard period of operation. Suits that are in individual use (operation) should be stored in a specially designated ventilated room on hangers or hung up. An important task in the development of a full pressure suit for a person is to ensure full mobility of its wearer without disrupting his physical capabilities (Iberall 1964). One of the directions of research that allows to improve the ergonomic characteristics of the developed clothing, is a scientific approach to the problem of taking into account the direction, relative position and orientation of structural divisions relative to the moving parts of the figure (Marreiros 2010, Newman et. al. 2003)

Protective lightweight suits of open type consist of: a jacket with a one-piece hood, semi-jumpsuit with osouzki (foot protection in the form of rubber shoes attached to the semi-jumpsuits with a onepiece adhesive connection) and knee reinforcements, gloves and bags for storing and carrying personal protective equipment. A special lightweight fabric base with a double-sided rubberized coating is made using modernized technology to make such suits lightweight.

In most cases protective isolation suits consist of a comfortable jumpsuit with a wide range of sizes and heights; protective vest with large panoramic glass; gas tight zipper; fabric with a special rubber (Lisitsyn et. al. 2011) double-sided coating based on durable nylon fabric. The suit is supplied with protective boots with composite toe caps and a non-piercing insole. A system of boots fastening with rigid rings allows the worker to replace boots on his own. Certified protective gloves that are resistant to chemical and heat-resistant substances up to $+250{ }^{\circ} \mathrm{C}$ are used to protect hands. Doublesided sealing of suit seams; reliable double exhalation valve with additional diaphragm and rubber protective cover; additional sealing sleeve latex cuffs; frost-resistant elastic face seal; obturator tension adjustment system; suit volume control system; adjustable valve for automatic air supply for the undersuit space are also used. The breathing apparatus is located outside the suit and is 
protected by a vest with panoramic glass or is located in the undersuit space. In particular models of protective suits, a compressed air breathing apparatus is worn under the suit. Sealing of these suits in most cases is carried out by smearing the seams with liquid rubber glue on the front side or on both sides. Seams sealing is performed after joining the parts with thread stitches in the following sequence: middle seam, elbow, shoulder, step, and seam of stitching in sleeves. In modern native insulating suits production, in most cases the combined (thread-hot-melt) types of seams are used.

The described above suits are used in the military, chemical industry, in areas contaminated with poisonous and emergency-chemical hazardous substances, as well in the course of hydraulic engineering works.

The breathing elements analysis showed that the autonomous type breathing elements have a complex volumetric design that should also be protected from the liquid phase of toxic substances. When entering the hazard class five zone, complete isolation from the environment is required and that fact leads to the design of the following features:

- a backpack of various modifications on the back side, if the element is attached to the back;

- a large amount of internal space in the front, due to large increases if the element is located in front;

- to relieve excess pressure in the undersuit space, it is necessary to use relief valves that should also be protected with material;

- for various types of devices fastening, it is necessary to insert an adapter into the suit that will be hermetically attached to it;

- to protect the head from mechanical shock, it is necessary to supply the suit with a helmet or a protective cap, therefore, there should be necessary volume in the upper part of the hood. In this case, the helmet should be attached to the suit in such a way as to exclude the leakage of polluted air and make its replacement and repair possible.

Insulating suits of different designs are manufactured due to different configuration of the breathing elements. It is not economically profitable for enterprises.

The analysis of breathing elements and isolation suits has generated interest in the creation of a universal suit that makes it possible to use various breathing elements.

\section{Materials and Methods}

At the first stage of the study, materials and methods of manufacturing a universal insulating chemical suit were selected.

The choice of connection method and seams design depends on the type of materials to be joined and the purpose of the jumpsuits. In accordance with the analysis carried out, the following materials turned out to be the most often used in the native insulating chemical suits production: T15, UNKL, Imera, 1542/200.

The seams sealing is achieved by coating the seams with liquid rubber glue on the front side or on both sides. The seams sealing is performed after joining the parts with thread stitches in the following sequence: middle seam, elbow, shoulder, step, and seam of stitching in sleeves. During the research, tapes 1045, HTR600.20.16 and 230-2T were used to seal the seams. Seams were sealed using a SportTex EU-7700N (China) heat sealing machine. The machine consists of the following elements: taped tape reel, taped tape frame, upper pneumatic cylinder, heat gun cylinder, exhaust pipe, heater, upper support, lower support, work surface, bed, fan, air regulation valve, left pedal, right pedal, flexible air duct, heater tip, protective cover, lower roller, elbow cover, temperature control device, control screen, power switch, upper roller pressure gauge, upper roller 
adjuster, distribution board, main control valve, oil spray, main pressure gauge. The roller pressure is $1-1.5 \mathrm{~kg} / \mathrm{cm}^{2}$, speed is $6-8 \mathrm{~m} / \mathrm{min}$, the glue melting point is $90-120^{\circ} \mathrm{C}$.

In accordance with GOST 12.4.220, the materials of insulating suits are "resistant" to aggressive environment, if the resistance indicator is greater than or equal to $90 \%$. If the indicator is from $75 \%$ to $90 \%$, then the material is regarded to as limitedly resistant. As a result of this experiment, it was found that if the suit will be used for work under constant exposure to this aggressive environment, then it is necessary to use the tape HTR600.20.16 and 230-2T, and the 1542/200 and Imera materials. If the suit is intended for short-term contact with this aggressive environment with subsequent quick cleaning, then we use tape 1045 with materials 1542/200, Imera and T-15.

In the manufacture of insulating suits from rubberized materials, there is no possibility of using wetheat treatment. In this regard, when making insulating suits from these materials, the wet-heat treatment is replaced by their tuning. Relying on the above mentioned sources, we can conclude that when developing resource-saving technologies for insulating suits manufacturing, it is advisable to use an overlapped seam sealed on both sides with an adhesive tape and an overlapped seam sealed on the front side.

For the universal protective insulating chemical suit, the material 1542/200 was chosen, the tape for sealing joints HTR600.20.16. The main seams (middle, step, sleeve stitching seam) are overlapped, with a stitch length of $3 \mathrm{~mm}$.

In most cases, at the moment, in the native insulating suits production, combined (thread-hot-melt) types of seams are used.

Basically, at the moment, machines of automatic or semi-automatic operation are used, as well as two-needle machines that perform two lines of the same or different weaving.

In the case of the jumpsuit-to-foot protection knots, it was found that it is better to use boots with an anti-puncture insole in protective suits. If the production of osoyuzok (a footwear semi-finished product made of rubber and knitted fabric) is available at the enterprise, the production of, a suit with a one-piece joint of the jumpsuits with a means of legs protection will have the form of a resource-saving technology.

In the case of making the hood of an insulating suit, the most time consuming is the connection of the front part of the hood of the jumpsuits with a panoramic glass or mask. The native costume manufacturers' analysis has revealed that the use of panoramic glass leads to an increase in the surrounding visibility at least $77 \%$ of the total field of view.

\section{Results and Discussion}

According to the experiments' results and breathing elements' analysis, a universal chemical insulating suit with increased reliability has been developed.

The suit is made in the form of an overall made of rubberized material vendor code 1542/200 and an HTR 600.20.16 adhesive tape. The jumpsuit is supplied with a set-in hood, an adjustable set-in backpack and stitched stockings. The back of the stocking is duplicated with flannel from the seamy side. The jumpsuit has a vertical split on the left side of the front, passing into the hood. The split is treated with a splash-proof chemical-resistant zipper, an internal insert that closes with a flexible magnetic tape, elastic "Velcro" contact tape and an additional top bar fastened with a "Velcro" contact tape. Protective boots are used in the suit.

There is a pocket with a flashlight above the panoramic glass. There is an adapter hidden in a protective pocket under the panoramic glass. On the back of the hood there is a strap fastened with metal half rings to adjust the hood with panoramic glass vertically. Under the protective pocket, fastened with a textile "contact" fastener there is an overpressure relief valve. The bottom of the sleeve of the jumpsuit can be made in two versions. 
Variant 1. The bottom of the sleeve ends with a rigid ring KF 06-002 and a rubber sleeve cuff, fixed from the seamy side with an elastic ring and two or three turns of adhesive tape. Sleeve cuffs provide the hands' tight fit (they can be cut depending on the hands size), ensure the tightness of the sleeves when changing protective gloves.

Variant 2. The bottom of the sleeve ends with a VKYAP.240.199.260 cuff and a rubber cuff (sewn into the sleeve), fixed from the front side of the sleeve with a clamp covered with an elastic ring. The glove is placed in the outer ring of the cuff, fixed with the inner ring and is attached to the cuff using a bayonet connection. The cuff with an outer ring is fixed with a tie.

Knitted cotton gloves are used to improve the physiological hygiene of hands, as well as to warm hands when working with cryogenic chlorine, ammonia, at subzero temperatures of the surrounding air and are worn directly on the hands. Protective gloves are worn on knitted gloves, additionally fixed with elastic rings, which are closed with gloves' lapel. Removable protective gloves provide additional sealing of sleeves, protection of hands from chemically hazardous substances' vapors, solutions of acids and alkalis, additional protection from mechanical stress.

The jumpsuit's body is a one-piece back half, its legs end with stitched stockings made of rubberized material, tied with an elastic band. On the back of the jumpsuit there is structural volume for the respiratory system balloons. The volume is regulated by straps fastened to metal half rings. On the jumpsuit's legs, just below the knee line, there are one overpressure relief valves. The flaps are covered with protective pockets fastened with a "Velcro" textile fastener. There are lightreflecting tapes on the sleeves and legs. On the right leg there is a stitched pocket for a repairs set where a knife and rubber gloves can be found. Three overpressure relief valves help remove anthropotoxins from the sub-suit space.

All seams of the jumpsuit, hood, backpack and stockings are finished with a stitching seam, glued with HTR600.20.16 adhesive tape.

The panoramic glass was glued using 88-NP glue.

The suit is used with head protection equipment: a helmet or protective cap.

If the suit is supposed to be used with an oxygen-breathing protective mask (such as IP-4, IP-5, IP6 , etc.), then for this type of personal respiratory system protective equipment, the regeneration unit is intentionally brought out for quick replacement of the RP and placed in a separate bag which is included in the package. The bag has openings for the used oxygen outlet and straps for the bag fastening. Shoulder and waist straps allow you to attach the bag to the suit.

To transfer the suit to the place of work, a portable bag is used. The portable bag is made of rubberized material with a shoulder strap, a loop for hand carry from the side, a connector located on the front and passing to the sides. The connector of the bag is closed with a zipper and covered with a strap fastened with a textile fastener.

The suit provides protection for the skin and respiratory organs of the worker due to the protective properties and impermeability of the material which it is made of, the tightness of the structure, and also due to the use of a breathing apparatus. The jumpsuits are made using threads 70 LL/2500 on a lockstitch sewing machine with differential material advance from JACK JK 6658, China.

The distance from the cuts to the line is $(7+1) \mathrm{mm}$. The ends of the stitches are secured with additional stitch from 10 to $30 \mathrm{~mm}$ long at a distance of 1-2 $\mathrm{mm}$ from the main stitch or a reverse stitch in the shape of the Russian letter "И". The total distance between the stitches is $(3 \pm 1) \mathrm{mm}$. Evaporation of moisture from the surface of the body is one of the main methods of heat transfer. In conditions of thermal comfort, no more than 40-50 g of moisture evaporates from the skin surface within an hour. Excretion of sweat in excess of $150 \mathrm{~g} / \mathrm{h}$ is associated with thermal discomfort (Schrobsdorff 2006). In view of the above, four holes are cut on the hood and legs, for the 
exhalation valve saddle with a diameter of $18 \mathrm{~mm}$. An amplifier made of rubberized material or vulcanized rubber. Pockets are sewn on the front side of the overalls to cover the flap holes. The width of the stitching seam is $(5 \pm 1) \mathrm{mm}$, at the ends of the stitching, triangular bartacks with a length of 8-10 $\mathrm{mm}$ should be sewn (Zaripov et. al. 2002).

Physically healthy people who have undergone medical examination in accordance with the established procedure, have studied the operating manual, have received solid skills in using an insulating breathing apparatus after training are allowed to work in the suit. The time spent by emergency crews in a contaminated area is regulated by the supply of air in the breathing apparatus. Only the suits in good shape in and self-contained breathing apparatus with an unexpired cylinder storage period are allowed for operation.

It is forbidden to use a suit: with an expired shelf life; not degassed and neutralized after the previous usage; having any damage, destruction from exposure to hazardous chemicals and aggressive environments. Any changes to the suit and isolating breathing apparatus must be reported immediately to the supervisor. Before putting the suit on, the user should perform visual inspection, check for leaks and ensure that the suit is functioning properly. The user must know the design of the suit and be ready to put it on and take it off on his own.

1. Filtering gas masks (such as GP, PMG, MGP, PPM, etc.). The filter box is screwed through a special valve on the outer side of the suit, which, accordingly, in case of the box contamination, makes it possible to change it quickly. Inside the suit, the gas mask is connected to the valve with a special corrugated tube (with bayonet-threaded tips) that is included in the kit.

2. Filtering hose gas masks (such as PSh-1S, PSh-20, etc.). It is connected to the breathing valve of the environmental suit through a corrugated tube extending from the waist belt.

3. Isolating gas masks (type IP-4, IP-5, IP-6, etc.). For this type of personal protective equipment for the respiratory organs, the regeneration unit is specially placed outside for quick replacement of the RP and placed in a separate bag, which is included in the kit. The regeneration unit is connected to the suit's valve through a special corrugated tube. The bag has a compartment for a spare regenerative cartridge.

4. Isolating gas masks operating on compressed air (AP-96M, ASV-2, AIR, etc.). This type of gas masks is located in the space under the suit. An adjustable backpack is provided for the equipment of the breathing apparatus.

Additional features of the "Universal" suit are the following. The suit is equipped with a helmet. A complete set of replaceable protective films in order to reduce mechanical impact on the panoramic glass of the environmental suit are supplied with it. When the light is lowered, the suit is equipped with a powerful 500W LED rechargeable flashlight located on the front of the suit. The design provides an outer pocket where spare gloves (in case the main pair breaks) and a knife, which is used for emergency removal of the suit in force majeure situations. The set with the suit includes a modern anti-fogging agent; the sleeves of the suit end with rigid rubber sleeves on which protective gloves are pulled and fixed with a tight elastic ring that allows replacing them easily. The backpack (for balloons of the respiratory system) in the back area can be tightened with straps if other types of breathing apparatus are used. Each suit includes a repair kit. A special backpack bag is supplied for the convenience of transporting the suit.

Thus, the developed suit makes it possible to use various breathing apparatus without additional costs for purchasing specially designed suits.

\section{References}


TR CU - 019 - 2011 (2012). Technical Regulations of the Customs Union "On the safety of personal protective equipment." Decision of the Customs Union Commission dated December 9, 2011 No. 878. Decisions of the Eurasian Economic Commission Board, 221, 61.

Zaripov, I.N., Kashapov N.F., Matveeva, V.Yu., Shergina, I.I., Fatkhutdinov, R. Kh. Protective suit: patent for a useful model 56198 of the Russian Federation (2002), IPC A 62 B 17/00/; No. 2006117994; declared 05.24.02; publ. 09.10.06, Bul. No. 25.

Personal protective equipment - Propaganda - Main Directorate of EMERCOM of Russia in the Republic of Adygea. Electronic resource. Access mode: https://01.mchs.gov.ru/deyatelnost/poleznaya-informaciya/propaganda/individualnyesredstva-zashchity.

Lisitsyn, Yu.A., Bochkarjova, S.A., Kargin, Yu.M. (2011). Electrochemical variation of the radical cation amination of aromatics. Reaction Mechanisms and Organic Intermediates. Internat. Conf.: Book of Abstracts, 152.

Iberall, A.S. (1964). The use of lines of nonextension to improve mobility in full-pressure suits: research report. Ohio: Aerospace Medical Research Laboratories, Wright-Patterson Air Force Base.

Schrobsdorff, B. (2006). Protective Clothing. Health \& Safety International, 14.

Zhuravleva, N.L., Matyuhina, N.M. (2011). Improving underwear suit for the space suit. Abstracts of the International Korean-Chinese conference.

Marreiros, S.S.P. (2010). Skin Strain Field Analysis of the Human Ankle Joint. Lisbon.

Newman, D.J., Hoffman, J., Bethke, K., Blaya, J., Carr, C., Pitts, B. (2003). An astronaut —BioSuit\| system: exploration-class missions. NIAC: MIDÉ Technologies, TAI, Nov. 